\title{
Структурно-отраслевые сдвиги в регионах степной зоны России
}

\author{
А.А. Соколов ${ }^{凶}$, О.С. Руднева \\ Оренбургский федеральный исследовательский центр УрО РАН, Институт степи УрО РАН, \\ Российская Федераиия \\ (460000, г. Оренбург, ул. Пионерская, 11)
}

\begin{abstract}
Аннотация: Цель - рассмотреть трансформацию отраслевой структуры степных регионов России по основным видам экономической деятельности, включающие в себя различные компоненты отраслей производственного и непроизводственного сектора.

Maтериалы и методbl. Специфика анализа состоит в применение различных методологических подходов для определения структурно-отраслевых сдвигов: по специализации, по типам отраслей и по широте охватка.

Результаты и обсуждение. В регионах степной зоны происходит структурно-отраслевая перестройка экономики, затрагивающая широкий диапазон отраслей. Экономика регионов проходит этап догоняющего развития. Стабильно растет непроизводственный сектор, но доля промышленности и сельского хозяйства хотя и сокращается, но по-прежнему остается высокой. Из региональных особенностей можно выделить практически повсеместный рост непроизводственного сектора, значительный рост агропромышленного комплекса в традиционно аграрных регионах, а также незначительные изменения в регионах с относительно сбалансированной структурой экономики.

Bblвoдbl. На современном этапе одним из важнейших современных вызовов в аспекте устойчивого развития территории степной зоны России является диспропорция структурно-отраслевых сдвигов в экономике входящих в нее регионов.
\end{abstract}

Ключевые слова: степная зона, регионы России, структурно-отраслевые сдвиги, сельское хозяйство, промышленность, непроизводственная сфера.

Источник финансирования: Работа подготовлена в рамках темы государственного задания ААAA-A21-121011190016-1.

Для цитирования: Соколов А.А. Руднева О.С. Структурно-отраслевые сдвиги в регионах степной зоны России // Вестник Воронежского государственного университета. Серия: География. Геоэкология, 2021, № 3, с. 52-58, DOI: https://doi.org/10.17308/geo.2021.3/3600

\section{ВВЕДЕНИЕ}

Структура экономики регионов сложна и многомерна. Она включает сочетания отраслей производственной и непроизводственной сферы. При территориально-отраслевом разделении труда появляются различные региональные особенности. К основным факторам, влияющим на региональную специфику, мы относим экономико-географическое положение, обеспеченность природными ресурсами, социальные, демографические и национальные особенности. Вследствие этого отрасли хозяйства формируются на территориях с наиболее подходящими условиями для их развития, а особенности территориально-отраслевого разделения труда соз- дают специализацию в экономике регионов. Однако региональное структурно-отраслевое разделение труда с течением времени трансформируется под воздействием разнообразных экономических факторов, вследствие чего происходят территориальные структурно-отраслевые сдвиги $[1,2]$.

\section{МАТЕРИАЛЫ И МЕТОДЫ}

В исследовании проведен анализ современных структурно-отраслевых сдвигов в 17 субъектах федерации, которые частично или полностью располагается на степной зоне России. Данный макрорегион благодаря своему географическому положению и широтному простиранию обладает широким спектром для развития различных отраслей эконо-

(C) Соколов А.А., Руднева О.С., 2021

$\checkmark$ Соколов Александр Андреевич, e-mail: sokolovaa@rambler.ru

Контент доступен под лицензией Creative Commons Attribution 4.0 License. 
мики. Непрерывная полоса степной (в том числе лесостепной) зоны России охватывает значительное пространство площадью 1,7 млн км² или $10 \%$ площади страны. Вытянутая преимущественно в широтном направлении более чем на 3,5 тыс. км, она имеет протяжённость с севера на юг от 150 до 600 км $[3,6,9]$.

Региональный структурно-отраслевой сдвиг - взаимообусловленное, обратно-пропорциональное изменение как основных отраслей, определяющих специализацию и экономическое развитие территории, так и взаимодополняющих, что приводит к углублению или ослаблению региональной специализации. Из различных видов структурно-отраслевых сдвигов необходимо выделить следующие: 1 - по типам отраслей: общие и производственные; 2 - по типам специализации региона: моно-специализированные и поли-специализированные; 3 - по широте отраслей: внутриотрасле-
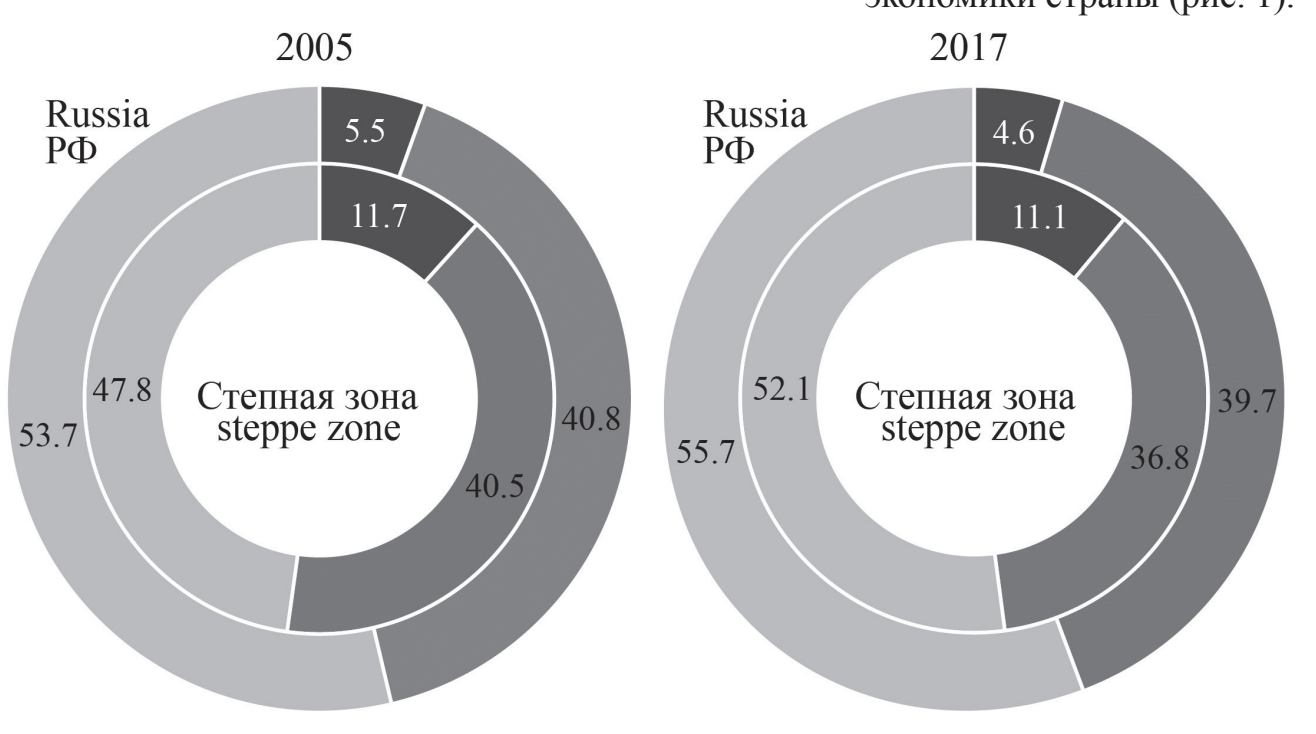

Сфера услуг services

Промышленность industry

Сельское хозяйство agriculture

Puc. 1. Динамика отраслевой структуры в РФ и степной зоне за 2005 и 2017 годы, в процентах

[Fig. 1. The dynamics of the sectoral structure in Russia and the steppe zone for 2005 and 2017, \%]

Проведенный анализ отраслевой структуры степной зоны и России показал двухкратное превышение доли сельского хозяйства в степных регионах. Так как степная зона России имеет более благоприятные природно-климатические условия для ведения сельского хозяйства, то это обуславливает существенно больший вклад данной отрасли в общую структуру экономики. Хотя доля промышленности и сферы услуг немного ниже в регионах степной зоны, чем по России в целом, но при этом существенно значимых различий нет.

Если проследить динамику структурно-отраслевого сдвига, как в степной зоне, так и по стране в целом, то здесь наблюдаются схожие изменения. Сокращается доля производственных отраслей и растет доля непроизводственного сектора [5]. Однако промышленное производство в регионах степной зоны сокращается существенно быстрее чем по стране. В период с 2005 по 2017 годы доля промышленности в степной зоне сократилась на 3,7\% с 40,5 до 36,6\%. За этот период снижение промышленности по стране составляло 1,1 \% с 40,8\% до 39,7. Если рассмотреть общее число закрытых промышленных предприятий, то из 797 крупных заводов 342 приходится на регионы степной зоны России. Отмечается сокращение отраслей сельскохозяйственного сектора с той лишь разницей, что в степной зоне это происходит менее значительно (на 0,6\%), в то время как в стране в целом отрасль сокращается на 0,9\% [4]. В то время как производство сокращается в непро- 
изводственном секторе происходит значительный рост. Прирост сферы услуг в степной зоне с 2005 по 2017 годы составил 4,3\%, что примерно в два раза выше темпа роста по стране - 2\%. За этот период регионы степной зоны в сравнение со страной оказались догоняющими в данной отрасли. Если в 2005 году отставание составляло 5,6\%, то к 2017 году оно сократилось до 3,6\%.

Рассматривая структурно-отраслевой сдвиг на региональном уровни, наблюдаются схожие тенденции (рис. 2). Если в 2015 году непроиз- водственный сектор был доминирующей отраслью для 10 из 17 регионов степной зоны России, то в 2017 году их количество увеличился до 13. Рост удельного веса за это период наблюдался в 10 регионах. Наибольший прирост пришелся на такие регионы как: Омская область - 12,7\%, Новосибирская - 9,9\% и Республика Башкортостан 9,8\%. Наибольший спад удельного веса отмечен в Тюменской области $-27,2 \%$. Но он обусловлен не столько сокращением непроизводственной сферы, сколько ростом объёмов в других отраслях.



Puc. 2. Динамика удельного веса основных видов деятельности в регионах степной зоны за 2005 и 2017 годы

[Fig. 2. The unit weight's dynamics of the main types of activity in the steppe zone regions for 2005 and 2017]

Количество регионов, в которых доминировало промышленное производство уменьшилось с 7 до 4, а сокращение удельного веса произошло в 11 регионах. Наибольший спад промышленной отрасли зарегистрирован в Омской области -11,7\% и в Республики Калмыкия -10,1\%. В то время как максимальный рост удельного веса промышленности произошел в Тюменской области. Он соста- вил $28,1 \%$. Такой существенный структурно-отраслевой сдвиг в промышленном производстве этого региона обусловлен ростом нефтехимического сектора, а также производством резиновых и пластмассовых изделий.

Сектор сельскохозяйственного производства не является доминирующей отраслью ни в одном из регионов степной зоны. Однако он существенно 
превышает среднее значение по другим регионам страны. Сокращение удельного веса сельского хозяйства в период с 2005 по 2017 годы наблюдалась в 12 из 17 регионах степной зоны. Наибольший спад был в Краснодарском крае $(-5,4 \%)$, Новосибирской $(-4,6 \%)$ и Курганской $(-3,8 \%)$ областях. Наибольший рост отмечен в таких значимых индустриально-аграрных регионах страны как Белгородская $(6,5 \%)$ и Воронежская $(3,8 \%)$ области.

По особенностям специализации большинство регионов степной зоны относится к поли-специализированным с высокой степенью диверсификации экономики. Два региона, Оренбургская область и Калмыкия, имеют ярко выраженную специализацию и их можно отнести к моно-специализированным. В Оренбургской области на долю добычи полезных ископаемых приходится около 40 \% валового регионального продукта. Такая ситуация ставит перед регионом серьезные социально-экономиче- ские и экологические вызовы в аспекте дальнейшего устойчивого развития. Республика Калмыкия - регион с низкой степенью диверсификации экономики. Здесь на долю сельского-хозяйства приходится около $30 \%$ валового регионального продукта, что в 6 раз превосходит данный показатель по России и практически в 3 раза больше, чем в регионах степной зоны.

Важнейшим показателем структурно-отраслевого сдвига является углубление специализации. Этот процесс непрерывный и он демонстрирует изменения объемов как доминирующих, так и прочих отраслей экономики [7]. В регионах степной зоны большая часть структурно-отраслевого сдвига приходится на доминирующие отрасли непроизводственного сектора экономики, но во многих регионах существенные структурно-отраслевые изменения затрагивают отрасли не доминирующие (рис. 3).

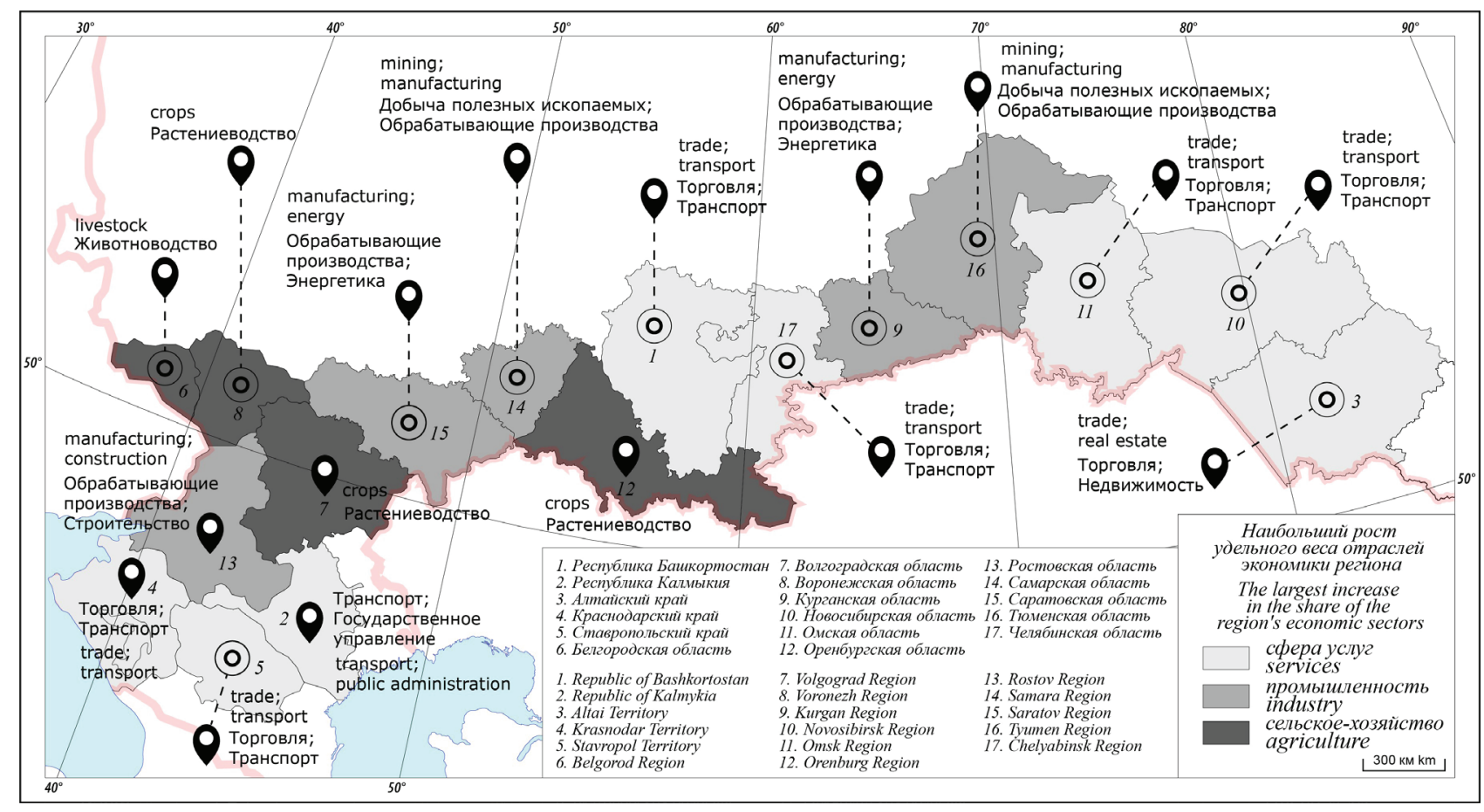

Рис. 3. Трансформация отраслевой структуры экономики регионов по доминирующим видам деятельности за 2005 и 2017 годы

[Fig. 3. Transformation of the sectoral structure of the regional economy, according to dominating types of activity for 2005 and 2017]

В 8-ми регионах степной зоны за период с 2005 по 2017 годы максимальный прирост в непроизводственном секторе пришелся на торговлю, транспорт, государственное управление и операции с недвижимостью. В 5-ти регионах наибольшим по приросту сектором экономики была промыш- ленность с преобладанием обрабатывающего производства, добычи полезных ископаемых, энергетики и строительства. Весомый вклад в развитие экономики степной зоны внесло сельское хозяйство в трех регионах наибольший рост связан растениеводством, а в одном с отраслью животноводства. 


\section{ЗАКЛЮЧЕНИЕ}

В последние десятилетия в регионах степной зоны происходит структурно-отраслевая перестройка экономики. Трансформация затрагивает широкий диапазон отраслей - сельское хозяйство, альтернативную энергетику, металлургию, торговлю, транспорта. Регионы степной зоны проходят этап догоняющего развития, уверено растет доля непроизводственного сектора. В настоящее время она составляет $52,1 \%$, однако это меньше средних показателей по стране - 55,7\% и намного ниже, чем по миру - 63 \%. При этом доля промышленности $(36,8 \%)$ и сельского хозяйства $(11,1 \%)$, хотя и сокращается, но по-прежнему остается высокой и превосходит сопоставимые мировые показатели (промышленность - $30 \%$, сельское хозяйство - 6,4\%). Данные структурные дисбалансы являются современными вызовами и требуют существенных усилий по их оптимизации $[8,10]$.

Из приведенного анализа современных структурно-отраслевых сдвигов в степной зоне можно выделить ряд региональных особенностей.

1. Значительный рост непроизводственного сектора (торговля, транспорт) за счет сокращения традиционных видов деятельности (обрабатывающие производства, добыча полезных ископаемых, сельское хозяйство): Омская, Новосибирская области, Краснодарский край, Республика Башкортостан и Калмыкия.

2. Существенный рост доли агропромышленного комплекса при сохранении значимости других отраслей промышленного производства и сферы услуг: Белгородская и Воронежская области.

3. Кардинальная трансформация структуры экономики (смена доминирующих отраслей - существенное сокращение доли сферы услуг при пропорциональном росте промышленности) Тюменская область

4. Незначительные изменения общей структуры при сохранении доминирующей роли традиционных отраслей экономики: Ставропольский край, Саратовская, Воронежская и Ростовская области.

5. Отсутствие значимых структурно-отраслевых сдвигов (практически полное сохранение пропорций между основными видами экономической деятельности): Самарская и Оренбургская области.

\section{СПИСОК ЛИТЕРАТУРЫ}

1. Антонюк В.С., Вансович Э.Р. Региональные отраслевые структурные сдвиги в моноспециализированных регионах // Экономические науки, 2010, № 73, c. 195-200.

2. Бакланов П.Я. Территориальные структуры хозяйства в региональном управление. Тихоокеанский институт географии ДВО РАН. Москва: Наука, 2007. 239 c.

3. Соколов А. А., Чибилёв А. А., Руднева О. С., Барбазюк Е. В., Дубровская С. А., Кин Н. О., Климентьев А. И., Левыкин С.В., Павлейчик В.М., Падалко Ю.А., Петрищев В.П., Поляков Д. Г., Рябуха А. Г., Сивохип Ж. Т., Чибилёв А.А. (мл.). Географический атлас Оренбургской области. Оренбург: Институт степи УрО РАН, РГО, 2020. $160 \mathrm{c}$.

4. Соколов А.А. Опыт территориальной оценки эффективности использования биопотенциального плодородия степной зоны России // Вестник Воронежского государственного университета. Серия: География. Геоэкология, 2018, №1, с. 73-77.

5. Ткаченко А. А., Фомкина А. А. География сферы обслуживания и география сектора услуг: пройденный путь, состояние, перспективы // Региональные исследования, 2016, № 3 (53), с. 5-13.

6. Чибилёв А.А. Природное наследие степей Евразии. Оренбург: Русское географическое общество, Институт степи Российской академии наук, 2014. 100 с.

7. Яковлева С.И. Устойчивость отраслевой структуры и специализации экономики регионов Центрального федерального округа России // Региональная экономика и управление: электронный научный журнал, №3 (59), 2019, c. 18 .

8. Joseph E. Stiglitz, Jean-Paul Fitoussi, Martine Durand. Measuring What Counts: The Global Movement for Well-Being. Organization for Economic Cooperation and Development, 2019. $256 \mathrm{p}$.

9. Sivokhip, Z.T., Pavleichik, V.M., Chibilev, A.A. et al. Problems of dependable water use in the transboundary Ural River basin // Water Resour, 2017, vol. 44, pp. 673-684.

10. The World Factbook, 2019-2020. 1176 p.

Конфликт интересов: Авторы декларируют отсутствие явных и потенциальных конфликтов интересов, связанных с публикацией настоящей статьи.

Поступила в редакциию 01.03.2021 Принята к публикации 03.09.2021 


\title{
Structural and Sectoral Shifts in the Regions of the Russian Steppe Zone
}

\author{
A.A. Sokolov $\bowtie$, O.S. Rudneva \\ Orenburg Federal Research Centre, Institute of Steppe of the Ural Branch \\ of the Russian Academy of Sciences, Russian Federation \\ (11, Pionerskaya Str., Orenburg, 460000)
}

\begin{abstract}
The purpose is to study sectoral structure transformation in steppe regions of Russia by major types of economic activity. The economy of steppe regions includes various components of producing and tertiary sectors. Materials and methods. The specifics of the analysis lie in the use of different methodological approaches to identify structural and sectoral shifts: by specialisation, by type of industry and by breadth of coverage. Results and discussion. The regions of the steppe zone are undergoing a structural and sectoral restructuring of their economies, affecting a wide range of industries. The economies of the regions are in a catching-up phase. The non-productive sector is growing steadily, but the share of industry and agriculture, although declining, is still high. Regional specifics include almost universal growth in the non-productive sector, significant growth in the agricultural sector in traditionally agrarian regions, and little change in regions with a relatively balanced economic structure. Conclusion. Disproportions in the structure and sectoral development of the steppe region's economy are among the most important current challenges for the sustainable development of Russia's steppe region at the present stage.
\end{abstract}

Key words: steppe zone, regions of Russia, structure and industry developments, agriculture, manufacturing industry, tertiary sector.

Funding: the study was carried out as part of the government assignment theme AAAA-A21-121011190016-1.

For citation: Sokolov A. A., Rudneva O.S. Structural and Sectoral Shifts in the Regions of the Russian Steppe Zone. Vestnik Voronezskogo gosudarstvennogo universiteta. Seria Geografia. Geoekologia, 2021, no. 3 , pp. 52-58 (In Russ.) DOI: https://doi.org/10.17308/geo.2021.3/3600

\section{REFERENCES}

1. Antonyuk V.S., Vansovich E.R. Regional'nye otraslevye strukturnye sdvigi v monospetsializirovannykh regionakh [Regional sectoral structural shifts in monospecialized regions Economic sciences]. Ekonomicheskie na$u k i, 2010$, no. 73, pp. 195-200. (In Russ.)

2. Baklanov P.Ya. Territorial'nye struktury khozyaystva $v$ regional'nom upravlenie [Territorial structures of economy in regional management]. Tikhookeanskiy institut geografii DVO RAN. Moskow: Nauka, 2007. 239 p. (In Russ.)

3. Sokolov A. A., Chibilev A.A., Rudneva O. S., Barbazyuk E. V., Dubrovskaya S.A., Kin N. O., Kliment'ev A.I., Levykin S.V., Pavleychik V.M., Padalko Yu.A., Petrishchev V.P., Polyakov D.G., Ryabukha A.G., Sivokhip Zh.T., Chibilev A.A. (ml.). Geograficheskiy atlas Orenburgskoy oblasti [Geographical atlas of the Orenburg
Region]. Orenburg, Institut stepi UrO RAN, RGO, 2020. 160 p. (In Russ.)

4. Sokolov A.A. Opyt territorial'noj ocenki jeffektivnosti ispol'zovanija biopotencial'nogo plodorodija stepnoj zony Rossii [The experience of territorial assessment of the effectiveness of the biopotential fertility use in the steppe zone of Russia]. Vestnik Voronezhskogo gosudarstvennogo universiteta. Seria: Geografia. Geojekologia. Geoecology, 2018, no. 1, pp. 73-77. (In Russ.)

5. Tkachenko A.A., Fomkina A.A. Geografiya sfery obsluzhivaniya i geografiya sektora uslug: proydennyy put', sostoyanie, perspektivy [Geography of the service sector and the geography of the service sector: the path taken, the state, the prospects]. Regional'nye issledovaniya, 2016, no. 3 (53), pp. 5-13. (In Russ.)

6. Chibilev A.A. Prirodnoe nasledie stepey Evrazii [Natural heritage of the Eurasian steppes]. Orenburg:

(C) Sokolov A. A., Rudneva O. S., 2021

$\triangle$ Alexander A. Sokolov, e-mail: sokolovaa@rambler.ru

The content is available under Creative Commons Attribution 4.0 License. 
Russkoe geograficheskoe obshchestvo, Institut stepi Rossiyskoy akademii nauk, 2014. 100 p. (In Russ.)

7. Yakovleva S.I. Ustoychivost' otraslevoy struktury i spetsializatsii ekonomiki regionov Tsentral'nogo federal'nogo okruga Rossii [Sustainability of the industry structure and specialization of the economy of the regions of the Central Federal District of Russia]. Regional'naya ekonomika $i$ upravlenie: elektronnyy nauchnyy zhurnal, 2019, no. 3 (59). (In Russ.)

8. Joseph E. Stiglitz, Jean-Paul Fitoussi, Martine Durand. Measuring What Counts: The Global Movement for Well-Being. Organization for Economic Cooperation and Development, 2019. 256 p.

\section{Соколов Александр Андреевич}

кандидат географических наук, старший научный сотрудник Оренбургского федерального исследовательского центра УрО РАН, Института степи УрО РАН, г. Оренбург, Российская Федерация, ORCID: 0000-00020093-3420, e-mail: sokolovaa@rambler.ru

Руднева Оксана Сергеевна

кандидат географических наук, старший научный сотрудник Оренбургского федерального исследовательского центра УрО РАН, Института степи УрО РАН, г. Оренбург, Российская Федерация, ORCID: 0000-00018425-3301, e-mail: ksen1909@mail.ru
9. Sivokhip, Z. T., Pavleichik, V. M., Chibilev, A. A. et al. Problems of dependable water use in the transboundary Ural River basin. Water Resour, 2017, vol. 44, pp. 673-684.

10. The World Factbook, 2019-2020. 1176 p.

Conflict of interests: The authors declare no information of obvious and potential conflicts of interestrelated to the publication of this article.

Received: 01.03.2021

Accepted: 03.09.2021

Alexander A. Sokolov

Cand. Sci. (Geogr.), Senior Researcher of the Orenburg Federal Research Centre, Institute of Steppe of the Ural Branch of the Russian Academy of Sciences, Orenburg, Russian Federation, ORCID: 0000-0002-0093-3420, e-mail: sokolovaa@rambler.ru

Oxana S. Rudneva

Cand. Sci. (Geogr.), Senior Researcher of the Orenburg Federal Research Centre, Institute of Steppe of the Ural Branch of the Russian Academy of Sciences, Orenburg, Russian Federation, ORCID: 0000-0001-8425-3301, e-mail: ksen1909@mail.ru 